\title{
Coliformes totais e termotolerantes em bifes de carne bovina tratados com ácido lático e lactato de sódio*
}

\author{
Total and thermotolerant coliforms of beef steaks treated with \\ sodium lactate and lactic acid
}

Karoline Mikaelle de Paiva Soares, ${ }^{* *}$ Lara Barbosa de Souza, ${ }^{* *}$ Jean Berg Alves da Silva***

\begin{abstract}
Resumo
A carne bovina é um alimento susceptível à deterioração microbiana e, por essa razão, o emprego de métodos de conservação pode ajudar na sua preservação. Uma forma de se avaliar a qualidade de carnes é através da análise de coliformes. Sendo assim, com o presente estudo, objetivou-se avaliar o uso de ácido lático e lactato de sódio no número mais provável de coliformes totais e termotolerantes em bifes de carne bovina. Para tanto, a partir de peças de carne embaladas a vácuo e com selo de inspeção federal, foram produzidos bifes de coxão mole submetidos à aplicação de tratamentos com ácido lático e seu sal sódico de forma isolada e combinada. Foram aplicados cinco tratamentos, sendo o primeiro o controle (ausência de imersão), o segundo a imersão em água destilada estéril, o terceiro e quarto corresponderam respectivamente à lavagem em solução de ácido lático e lactato de sódio de forma isolada e no quinto tratamento, os bifes foram tratados com esses aditivos de forma combinada. Os bifes foram submetidos à contagem de coliformes totais no tempo zero e a cada 72 horas durante nove dias. As análises foram realizadas com três repetições por tratamento. $O$ tratamento combinado com os aditivos foi eficiente em inibir crescimento de coliformes totais e termotolerantes durante a estocagem em condições de refrigeração.
\end{abstract}

Palavras-chave: micro-organismos, qualidade, coxão mole bovino, tratamentos.

\begin{abstract}
Beef is a food susceptible to microbial spoilage and, therefore, the use of conservation methods can help in its preservation. One way of assessing meat quality are coliforms analysis. Thus, the present study aimed to evaluate the use of lactic acid and sodium lactate in the most probable number of total and fecal coliforms in beef steaks. Therefore, from pieces of meat vacuum packed and federal inspection stamp were produced steaks topside submitted to the application of treatments with lactic acid and its sodium salt isolated and combined. Five treatments were applied, the first control, the second immersion in sterile distilled water, the third and fourth correspond respectively to washing in lactic acid solution and sodium lactate alone and the fifth treatment, the steaks were treated with these additives in combination. The steaks were subjected to total coliform count at time zero and every 72 hours for nine days. Analyses were performed with three replicates per treatment. The combined treatment with the additives was effective at inhibiting growth of total coliforms and during storage under refrigerated conditions.
\end{abstract}

Keywords: micro-organisms, quality, soft beef cushion, treatments.

\section{Introdução}

Os alimentos fornecem nutrientes para o funcionamento adequado do organismo humano (Silva et al., 2015). No Brasil, a carne bovina representa uma das proteínas mais consumidas pela população (Lima Júnior et al., 2011), com destaque para o aumento na oferta e procura de carnes bovinas comercializadas na forma de bifes pré embalados nos estabelecimentos varejistas (Soares et al., 2015; Santos e Oliveira, 2012).

Os bifes de carne bovina são susceptíveis à contaminação microbiana por serem submetidas à manipulação, principalmente, durante as etapas de corte e embalagem e tendem a apresentar uma deterioração superficial ocasionada principalmente por bactérias (JAY, 2005). Para multiplicação, os micro-organismos precisam de condições favoráveis (Germano e Germano, 2008), que são suficientemente encontradas em carnes bovinas não processadas (Forsythe, 2013), assim como outros alimentos de origem animal (Rossi e Bampi, 2015).

Dessa forma, é importante se avaliar métodos que ajudem na conservação desse alimento. O emprego de ácidos orgânicos e seus sais vêm sendo avaliados com eficiência em produtos de origem animal (Huffman, 2002; Tan e Shelef, 2002; Pipek et al., 2005; Silva et al., 2014). Os coliformes podem ser avaliados para constatar a eficiência de tratamentos em alimentos. Estes microorganismos são considerados indicadores por poderem indicar a ocorrência de falhas em medidas de higiene durante a obtenção, processamento ou armazenamento de alimentos como os de origem animal (Franco e Landgraf, 2008). São representados pelos gêneros Enterobacter, Citrobacter, Klebsiella e Escherichia (Moura et al., 2007). Carnes bovinas contaminadas com

\footnotetext{
*Recebido em 2 de agosto de 2016 e aceito em 10 de fevereiro de 2017.

**Universidade Federal Rural do Semi-árido; Laboratório de Biotecnologia Industrial; Departamento de Ciência Animal; Mossoró; Rio Grande do Norte; Brasil. karolinesoares@ufersa.edu.br .

***Universidade Federal Rural do Semi-árido; Laboratório de Inspeção de Produtos de Origem Animal; Departamento de Ciência Animal; Mossoró; Rio Grande do Norte; Brasil.
} 
coliformes podem não apresentar alterações sensoriais que possam ser detectadas pelos órgãos de sentido do consumidor, sendo a detecção destes micro-organismos realizada através de análises microbiológicas (Muratori et al., 2000), como a técnica do número mais provável (NMP) (Brasil, 2003).

Sendo assim, o presente estudo objetivou determinar o número mais provável de coliformes totais e termotolerantes em bifes de carne bovina tratados com ácido lático e lactato de sódio utilizados de forma isolada e combinada.

\section{Material e métodos}

Durante o experimento, peças de coxão mole bovino embaladas a vácuo produzidas por matadouro-frigorífico com Serviço de Inspeção Federal foram adquiridas no comercio varejista local e transportadas em caixas isotérmicas ao Laboratório de Biotecnologia Industrial aplicada ao Processamento de Alimentos do Departamento de Ciências Animais da Universidade Federal Rural do Semiárido.

No local de processamento, a carne foi utilizada como matéria prima para produção de bifes de aproximadamente $100 \mathrm{~g}$ e $0,5 \mathrm{~cm}$ de espessura.

Os bifes foram submetidos à aplicação de tratamentos distintos: 1 (controle - não foi aplicado tratamento/ ausência de imersão); 2 (imersão em água destilada estéril por cinco minutos); 3 (imersão em solução de ácido lático a $1 \%$ por cinco minutos); 4 (imersão em solução de lactato de sódio a $3 \%$ por cinco minutos) e 5 (imersão em solução de lactato de sódio $3 \%$ e ácido lático a $1 \%$ por cinco minutos).

A concentração de lactato de sódio a 3\% foi baseada em recomendação de KaczmarekDuszek et al. (2008) para carne bovina moída e a de ácido lático a $1 \%$ na pesquisa de Grajales-Lagunes et al. (2012) em carne suína.

Após o processamento, as amostras foram estocadas em refrigeração em temperaturas entre $4^{\circ} \mathrm{C}$ e $7^{\circ} \mathrm{C}$ durante nove dias e submetidas a análises para a determinação do número mais provável de coliformes totais e termotolerantes no tempo zero e a cada 72 horas durante nove dias. As análises foram realizadas de forma asséptica em fluxo unidirecional. Pesou-se $25 \mathrm{~g}$ de cada amostra para diluição em $225 \mathrm{~mL}$ de água peptonada tamponada esterilizada em autoclave para obtenção da primeira diluição, e, a partir desta, foram obtidas as demais, $10^{-2}$ e $10^{-3}$. A determinação de coliformes totais foi realizada através de cultivo em banhomaria com caldo lauril sulfato de sódio seguido de caldo verde brilhante à $37^{\circ} \mathrm{C} \pm 1$ por 48 horas. Os tubos positivos foram repicados em caldo Escherichia coli para a determinação de coliformes termotolerantes com incubação à temperatura de $45^{\circ} \mathrm{C} \pm 1$ durante 48 horas. As análises foram realizadas com três $+1 \%$ Ácido lático) repetições por tratamento, sendo os resultados obtidos através de tabela de NMP por grama (BRASIL, 2003).

\section{Resultados e discussão}

As Figuras 1 e 2 demonstram a frequência de amostras de cada tratamento que apresentou NMP de coliformes totais e termotolerantes maior ou menor que três nos dias zero, 3, 6 e 9.

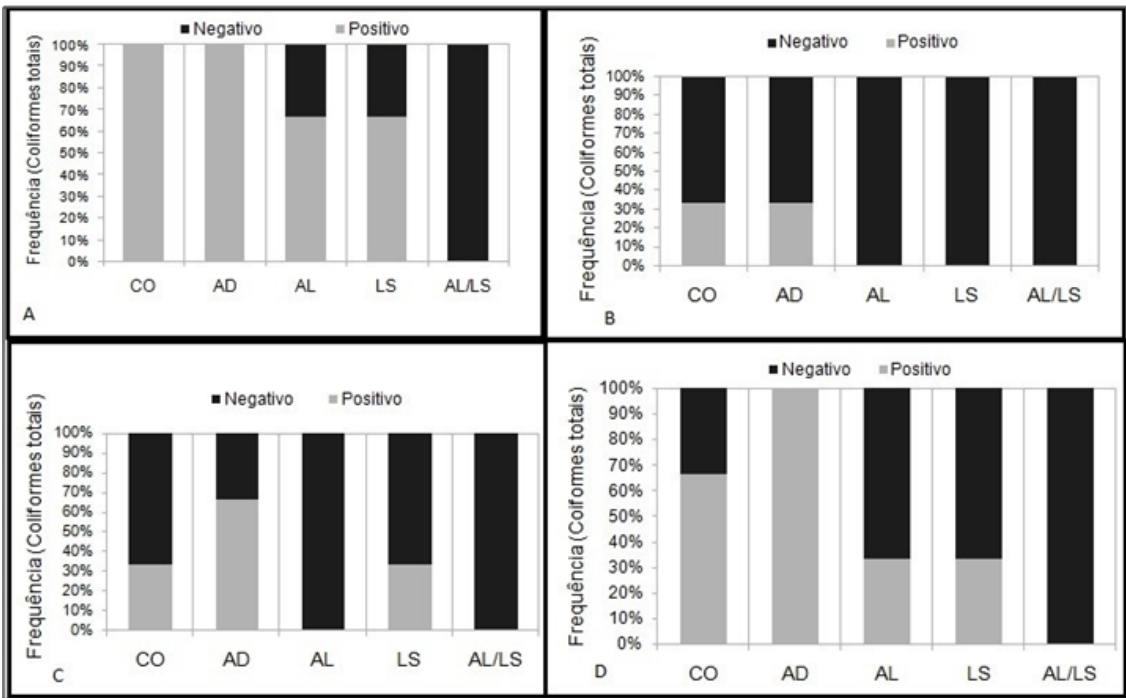

Figura 1: Frequência de resultados positivos e negativos para coliformes totais no dia zero (A), três (B), seis (C) e nove (D) (positivo: coliformes $>3 \mathrm{NMP} / \mathrm{g}$ - negativo: coliformes<3 NMP/g) em bifes de carne bovina após a aplicação de diferentes tratamentos (CO: Controle, AD: Água destilada, AL: $1 \%$ de Ácido lático, LS: $3 \%$ de Lactato de sódio e AL/LS: 3\% Lactato de sódio + 1\% Ácido lático)

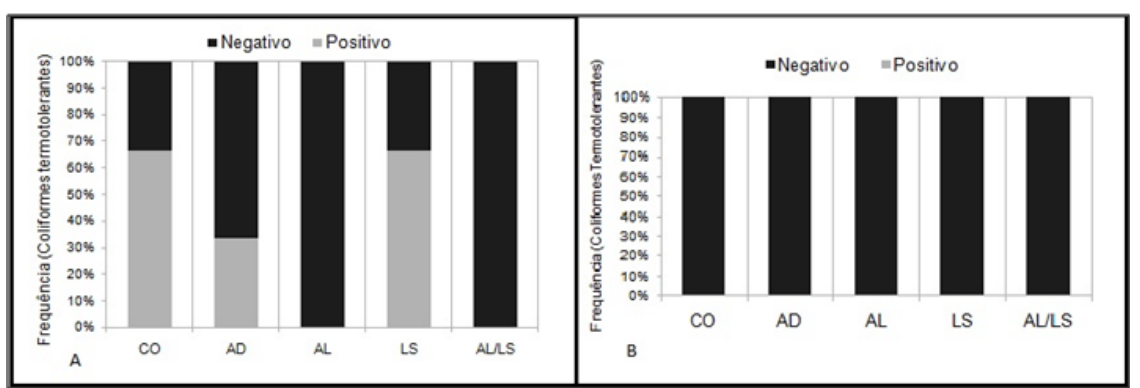

Figura 2: Frequência de resultados positivos e negativos para coliformes termotolerantes no dia zero (A) e para os dias três, seis e nove (B) (positivo: coliformes $>3 \mathrm{NMP} / \mathrm{g}$ - negativo: coliformes $<3$ $\mathrm{NMP} / \mathrm{g}$ ) em bifes de carne bovina após a aplicação de diferentes tratamentos (CO: Controle, AD: Água destilada, AL: $1 \%$ de Ácido lático, LS: $3 \%$ de Lactato de sódio e AL/LS: $3 \%$ Lactato de sódio

Os tratamentos em que não foram utilizados aditivos apresentaram uma frequência de $100 \%$ de coliformes totais nas amostras avaliadas no dia zero. Também foi verificada presença de coliformes em amostras tratadas de forma isolada com lactato de sódio e ácido lático.

$\mathrm{Na}$ análise do terceiro dia, $30 \%$ das amostras dos tratamentos controle e com água destilada apresentaram NMP de coliformes totais maior que três. Nos bifes dos demais tratamentos, o NMP de coliformes totais foi menor que três. Aos seis dias de estocagem, detectou-se presença de coliformes totais em amostras dos tratamentos controle, água destilada e lactato de sódio, com diferentes frequências. Enquanto que no nono dia 
de estocagem refrigerada, foi detectada presença de coliformes totais em amostras de todos os tratamentos, com exceção do tratamento combinado. Neste dia de análise, $100 \%$ das amostras avaliadas do tratamento com água destilada apresentaram NMP superior a três.

Apesar de não ser possível inferir que o uso isolado de lactato de sódio e ácido lático exerceu inibição efetiva sobre o NMP de coliformes totais, verificou-se que o uso combinado de lactato de sódio e ácido lático é capaz de inibir o crescimento de coliformes totais. Não foi detectado crescimento de coliformes totais em nenhuma amostra do tratamento combinado ao longo do armazenamento. Ao passo que, verificou-se crescimento de coliformes termotolerantes nas amostras apenas no dia zero nos tratamentos controle, água destilada e lactato de sódio. Os tratamentos com ácido lático e o combinado foram eficientes em evitar proliferação de coliformes termotolerantes. Durante a estocagem, constatou-se ausência no crescimento de coliformes termotolerantes. Esse resultado possivelmente pode ser explicado pelo potencial antimicrobiano dos ácidos orgânicos e seus sais em carnes e produtos cárneos (Silva et al., 2014; Tan e Shelef, 2002; Vasconcelos et al., 2002).

Possivelmente, a influência do lactato de sódio e ácido lático de forma isolada na contagem de coliformes totais e termotolerantes não ficou evidenciada de forma mais intensa devido às baixas contagens encontradas para este grupo microbiano no presente estudo, pois o NMP de coliformes totais variou de $<3$ a 210 $\mathrm{NMP} / \mathrm{g}$ e o de coliformes termotolerantes variou de $<3$ a 43 $\mathrm{NMP} / \mathrm{g}$. Quando as contagens microbiológicas da matéria-prima em relação a um determinado grupo microbiano são baixas, é difícil mensurar o efeito antimicrobiano dos ácidos orgânicos sobre estes micro-organismos (Prasai et al., 1992). Nascimento (2011) não conseguiu avaliar o efeito da utilização do ácido lático a 1 e $2 \%$ na contagem de coliformes em carne-de-sol devido à boa qualidade higiênico-sanitária da matéria-prima. Isto também foi constatado por Silva e Beraquet (1997) na sua pesquisa com carne bovina tratada com ácidos orgânicos.

As baixas contagens de coliformes totais e termotolerantes encontradas no presente estudo, possivelmente, estão relacionadas com as boas condições higiênico sanitárias de obtenção da matéria prima utilizada, além da adoção de boas práticas de higiene durante a manipulação e processamento dos bifes. Uma possível explicação para ausência de coliformes termotolerantes durante o armazenamento é a

\section{Referências}

BALDUINO, R.; OLIVEIRA, A.S.; HAULY, M.C.O. Cultura lática mista com potencial de aplicação como cultura iniciadora em produtos cárneos. Food Science and Technology (Campinas), v. 19, n. 3, p. 356-362, 1999.

BEYAZ, D.; TAYAR, M. The Effect of Lactic Acid Spray Application on the Microbiological Quality of Sheep Carcasses. Journal of Animal and Veterinary Advances, v. 9, n. 13, p. 1858-1863, 2010.

BRASIL. Ministério da Agricultura, Pecuária e Abastecimento. Instrução Normativa $\mathrm{N}^{\circ} 62$, de 26 de agosto de 2003. Oficializa os métodos analíticos oficiais para análises microbiológicas para controle de produtos de origem animal e água. Diário Oficial do Brasil, Brasília, DF, 26 ago. 2003. Seção I. inibição competitiva ocasionada por bactérias láticas frente aos coliformes que vem sendo confirmada em algumas pesquisas como a de Balduino et al. (1999).

Algumas pesquisas vêm destacando o efeito inibitório principalmente do ácido lático em coliformes. Silva et al. (2001) ao aplicar solução de ácido lático a 1 e $2 \%$ em carcaças de frango constatou uma redução significativa no número mais provável de coliformes. $O$ tratamento com $1 \%$ de ácido lático reduziu em 0,71 e 0,62 log NMP/ $\mathrm{cm}^{2}$ ciclos logarítmicos na contagem de coliformes totais e termotolerantes, respectivamente. E, com a utilização de aspersão com solução de ácido lático a $2 \%$, os autores acima mencionados observaram efeitos ainda mais significativos, com redução de 1,40 e 1,31 ciclos logarítmicos nas contagens de coliformes a $35^{\circ}$ e a $45^{\circ} \mathrm{C}$, respectivamente (Silva et al., 2001).

Castillo et al. (1998) verificaram que o uso combinado de água de lavagem quente e pulverização com ácido lático pode reduzir a quantidade de coliformes em carcaças bovinas. Gill e Badoni (2004) constataram que o uso de solução a $4 \%$ de ácido lático em peças de carne promove uma redução de cerca de 1,5 ciclos logarítmicos de coliformes em relação às peças tratadas com água. Beyaz e Tayar (2010), ao sanitizarem carcaças ovinas com solução de ácido lático a $1 \%$, verificaram que este aditivo é capaz de reduzir a população de coliformes em 2,69 ciclos logarítmicos após 30 minutos e em 2,16 ciclos após 24 horas. Ao utilizarem solução de $2 \%$, estes autores encontraram efetividade ainda maior, com redução de 2,98 e 2,31 ciclos logarítmicos, respectivamente. Vasconcelos et al. (2002), ao trabalharem com carne ovina tratada com $1 \%$ de ácido acético, também constataram a eficiência de ácidos orgânicos sobre coliformes, com redução em aproximadamente 1 log na contagem de coliformes totais.

\section{Conclusão}

A aplicação de ácido lático e lactato de sódio de forma isolada não inibiu completamente o crescimento de coliformes totais e termotolerantes. No entanto, em amostras tratadas com aditivos de forma combinada não foi constatado crescimento de coliformes a $35^{\circ}$ e $45^{\circ} \mathrm{C}$. Assim, o uso combinado de ácido lático e lactato de sódio pode ser uma alternativa eficiente em reduzir o crescimento de micro-organismos indicadores em bifes de carne bovina.

CASTILLO, A., L. M. LUCIA, K. J. GOODSON, J. W. SAVELL, G. R. ACUFF. Comparison of water wash, trimming, and combined hot water and lactic acid treatments for reducing bacteria of fecal origin on beef carcasses. J. Food Prot. 61:823-828, 1998.

FORSYTHE, S.J. Microbiologia da segurança dos alimentos. 2. ed. São Paulo: Artmed, 2013. 607 p.

FRANCO, B. D. G.; LANDGRAFF, M. Microbiologia dos alimentos. São Paulo: Atheneu, 2008. 182 p.

GERMANO, P. M. L.; GERMANO, P. M. L. Higiene e vigilância sanitária de alimentos. 3. ed. São Paulo: Manole, 2008, 986 p.

GILL, C. O.; BADONI, M. Effects of peroxyacetic acid, acidified sodium chlorite or lactic acid solutions on the microflora of chilled beef carcasses. International Journal of Food Microbiology, v. 91, n. 1, p. 43-50, 2004. 
GRAJALES-LAGUNES, A.; RIVERA-BAUTISTA, C.; RUIZCABRERA, M.; GONZALEZ-GARCIA, R.; RAMIREZ-TELLES, J.; ABUD-ARCHILA, M. Effect of lactic acid on the meat quality properties and the taste of pork Serratus ventralis muscle. Agricultural and Food Science, v. 21, n. 2, p. 171-181, 2012.

HUFFMAN, R. D. Current and future technologies for the decontamination of carcasses and fresh meat. Meat Science, v. 62, n. 3, p. 285-294, 2002.

JAY, J. Microbiologia de Alimentos. $6^{\mathrm{a} E d . ~ S a ̃ o ~ P a u l o: ~ A r t m e d . ~}$ 2005, 712p.

KACZMAREK-DUSZEK, J.; BILSKA, A., KRYSZTOFIAK, K., UCHMAN, W. The effect of selected technological additives on improvement of shelf life of ground meat. Acta Scientiarum Polonorum. Technologia Alimentaria, v. 7, n. 2, p. 51-61, 2008.

LIMA JÚNIOR, D.M.; RANGEL, A.H.N.; URBANO, S.A.; MACIEL, M.V.; AMARO, L.P.A. Alguns aspectos qualitativos da carne bovina: uma revisão. Acta Veterinaria Brasilica, v. 5, n. 4, p. 351358, 2011.

MOURA, A. P. B. L.; PINHEIRO JUNIOR, J. W.; OLIVEIRA, R. B. A.; DUARTE, D. A. M.; REIS, E. M. F. Pesquisa de coliformes termotolerantes, totais e Salmonella spp. Em carnes caprinas comercializadas na cidade do Recife, Pernambuco. Arquivos do Instituto Biológico, v. 74, n. 4, p. 293-299, 2007.

MURATORI M. C. S., OLIVEIRA A. L., RIBEIRO L. P., COSTA A. P. R., FERNANDES S. H., LEITE R. C. Corporacion entre el método estándar sugerido por Aphay los métodos simplate y pentifilm, para la identificacion del grupo coliforme y de escherichia coli en tilapia (Oreochremis sp) piocedente de piscicultura de água Dulce. Revista Argentina de Microbiologia, v.32, p.15-19, 2000.

NASCIMENTO, E. P. S. Efeito do ácido lático sobre as características microbiológicas, físico-químicas e sensoriais na carne do sol. 2011. 88 f. Dissertação (Mestrado) - Departamento de Engenharia Química - Universidade Federal do Rio Grande do Norte, Natal, 2011.

PIPEK, P.; HOUSKA, M.; JELENÍKOVÁ, J.; KÝHOS, K.; SIKULOVÁ, M. Microbial decontamination of beef carcasses by combination of steaming and lactic acid spray. Journal of Food Engineering, v. 67, n. 3, p. 309-315, 2005.
PRASAI, R. K.; ACUFF, G. R.; LUCIA, L. M.; MORGAN, J. B.; MAY, S. G.; SAVELL, J. W. Microbiological effects of acid decontamination of pork carcasses at various locations in processing. Meat science, v. 32, n. 4, p. 413-423, 1992.

ROSSI, P.; BAMPI, G.B. Qualidade microbiológica de produtos de origem animal produzidos e comercializados no Oeste Catarinense. Segurança Alimentar e Nutricional, v. 22, n. 2, p. 748-757, 2015.

SANTOS, J.S.; OLIVEIRA, M.B.P.P. Alimentos frescos minimamente processados embalados em atmosfera modificada. Brasilian Journal of Food Technology, v. 15, n. 1, p. 1-14, 2012.

SILVA, J. A.; BERAQUET, N. J. Redução da contaminação inicial de carne bovina pela sanitização com ácidos orgânicos. Boletim do Centro de Pesquisa de Processamento de Alimentos, v. 15, n. 2, 1997.

SILVA, J.A.; SOARES, L.F.; COSTA, E.L. Sanitização de carcaças de frango com soluções de acidos orgánicos comerciais e suco de limão. Revista Tecnologia de Carnes, v.3, n.1, p.19-26, 2001.

SILVA, R.R.L.; GOUVEIA, D.S.; ROCHA, A.P.T.; ARAÚJO, A.S. Análise de coliformes e verificação das Boas Práticas de Fabricação de carne moída comercializada na cidade de Campina Grande-PB. Revista Verde de Agroecologia e Desenvolvimento Sustentável, v. 10, n.1, p.115-119, 2015.

SILVA, R.X.A.; CAMPOS JOSÉ, K.F.; FRANCO, R.B.; SILVA, T.J.P. Lactato de sódio, nisina e sua combinação na validade comercial da linguiça Toscana embalada a vácuo e estocada a $4^{\circ} \mathrm{C}$. Ciência Rural, v. 44, n. 4, 2014.

SOARES, K.M.P; SILVA, J.B.A; SOUZA, L. B.; MENDES, C. G.; ABRANTES, M. R.; CAMPELO, M. C.; SOUZA, A. S. Qualidade microbiológica de carne bovina comercializada na forma de bife. Revista Brasileira de Ciência Veterinária, v. 22, n. 3-4, 2015.

TAN, W.; SHELEF, L.A. Effects of sodium chloride and lactates on chemical and microbiological changes in refrigerated and frozen fresh ground pork. Meat Science, v. 62, n. 1, p. 27-32, 2002.

VASCONCELOS, E.C.; ZAPATA, J.F.F.; FIGUEIREDO, E.A.; BRANCO, M.A.A.C.; BORGES, A.S. A microbiota da carcaça e da carne ovina tratada com ácido acético, embalada a vácuo e maturada por 48 dias. Ciência e Tecnologia de Alimentos, v. 22, n. 3, p. 272-277, 2002. 